\title{
Sequential Catalytic Functionalization of Aryltriazenyl Aldehydes for the Synthesis of Complex Benzenes
}

\author{
Sangwon Seo, Ming Gao, Eva Paffenholz, and Michael C. Willis*
}

Cite This: ACS Catal. 2021, 11, 6091-6098

Read Online

ABSTRACT: We demonstrate that aryltriazenes can promote three distinctive types of $\mathrm{C}-\mathrm{H}$ functionalization reactions, allowing the preparation of complex benzene molecules with diverse substitution patterns. 2-Triazenylbenzaldehydes are shown to be efficient substrates for $\mathrm{Rh}(\mathrm{I})$-catalyzed intermolecular alkyne hydroacylation reactions. The resulting triazene-substituted ketone products can then undergo either a $\mathrm{Rh}(\mathrm{III})$-catalyzed $\mathrm{C}-\mathrm{H}$ activation, or an electrophilic aromatic substitution reaction, achieving multifunctionalization of the benzene core. Subsequent triazene derivatization provides traceless products.

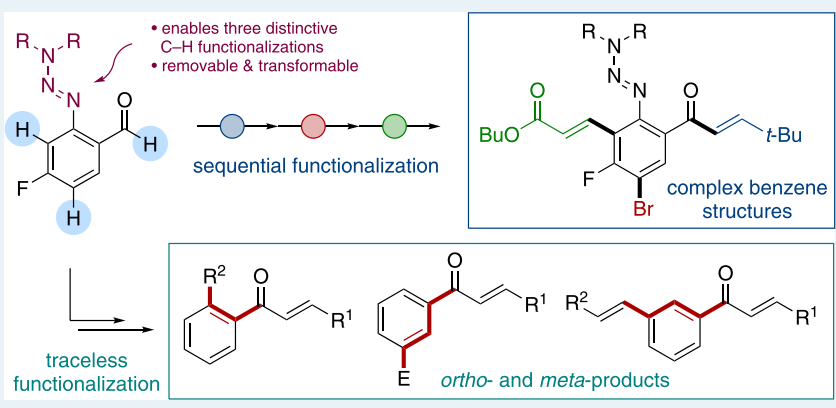

KEYWORDS: hydroacylation, rhodium, triazene, benzene, sequential catalysis

G iven the abundance of $\mathrm{C}-\mathrm{H}$ bonds in organic molecules, the functionalization of these bonds represents an ideal method for chemical manipulation. ${ }^{1}$ Transition-metal catalysis has played a significant role in the advancement of this field, providing powerful methods that are comparable to conventional metal-catalyzed cross-coupling reactions. ${ }^{2}$ In particular, the use of directing group strategies has been the dominant approach to achieve regioselective reactions. ${ }^{3}$ A limitation of such strategies is that the coordinating group, which, by design, is present to direct the metal catalyst to specific $\mathrm{C}-\mathrm{H}$ bonds of the starting material, will also be present in the final product. This limits synthetic flexibility, and, thus, the ability to remove or transform the directing group to other useful functionalities is advantageous. In addition, it would be beneficial if the coordinating group was able to promote, not only one, but multiple $\mathrm{C}-\mathrm{H}$ functionalization reactions in a selective way., ${ }^{4,5}$

Metal-catalyzed hydroacylation reactions are examples of $\mathrm{C}-\mathrm{H}$ functionalizations in which the $\mathrm{C}-\mathrm{C}$ multiple bond of an alkene or alkyne inserts into the formyl $\mathrm{C}-\mathrm{H}$ bond of an aldehyde. $^{6,7}$ Despite the advent of several non-chelationcontrolled methods for hydroacylation reactions, ${ }^{8}$ intermolecular versions of these processes based on the use of some form of substrate chelation remain the most common. ${ }^{9}$ Aldehydes featuring $\mathrm{P}-_{-}{ }^{10} \mathrm{O}-{ }^{11}{ }^{11} \mathrm{~N}-,{ }^{12}$ and S-based chelating groups, ${ }^{13}$ as well as chelating alkenes, ${ }^{14}$ have all been used, and reactions that proceed under mild reaction conditions and encompass broad substrate scopes have been achieved. Regio- ${ }^{9 e, f, 12,15 \mathrm{f}}$ and enantioselective $^{16}$ reactions have also been reported, ${ }^{15 b, 17}$ and applications have been developed. ${ }^{11 \mathrm{~b}, 18}$ With these advances in place, strategies to mitigate the issues associated with the presence of chelating-substituents are needed. In this context, approaches have been developed where the chelating group is either incorporated into a target structure, ${ }^{18 \mathrm{f}, 19}$ or transformed to an alternate functionality. ${ }^{18 \mathrm{~g}, 20}$ For example, our laboratory has shown that a chelating methyl sulfide employed in hydroacylation reactions can be directly utilized in subsequent $\mathrm{Rh}$-catalyzed carbothiolation, arylation, or reduction reactions (see Scheme 1a). ${ }^{21}$

Building on these prior reports, we aimed to develop an alternative chelating group that would provide complementary transformations and functionalization opportunities. We were particularly interested in an approach in where the coordinating group would be capable of promoting further $\mathrm{C}-\mathrm{H}$ functionalization reactions, allowing the use of simple substrates, and access to a variety of substitution patterns. In this context, Jun has reported a cascade strategy that uses insitu-generated picolyl imines for alkene hydroacylation and ortho-alkylation of benzaldehydes (Scheme 1b). ${ }^{22}$ This double $\mathrm{C}-\mathrm{H}$ functionalization is assisted by a single chelating group. However, the harsh reaction conditions $\left(170{ }^{\circ} \mathrm{C}\right.$ reaction temperature) result in little regiocontrol, which, in turn, limits the functionalization at both $\mathrm{C}-\mathrm{H}$ sites to the same coupling partner. The synthetic utility of this approach would be significantly improved if the distinct $\mathrm{C}-\mathrm{H}$ bonds could be selectively functionalized using different coupling partners. ${ }^{4}$ To achieve these aims, we selected aryl aldehydes substituted with

Received: April 15, 2021

Revised: April 29, 2021

Published: May 5, 2021 
Scheme 1. (a) Hydroacylation and Subsequent C-S Functionalization, $^{21}$ (b) Cascade Hydroacylation/ortho-CH Alkylation, ${ }^{22}$ (c) 2-Triazenyl-benzaldehydes in Hydroacylation and Sequential $\mathrm{C}-\mathrm{H}$, Triazene Functionalization, and $\mathrm{E}^{+}$Substitution

a) Hydroacylation/C-S functionalization

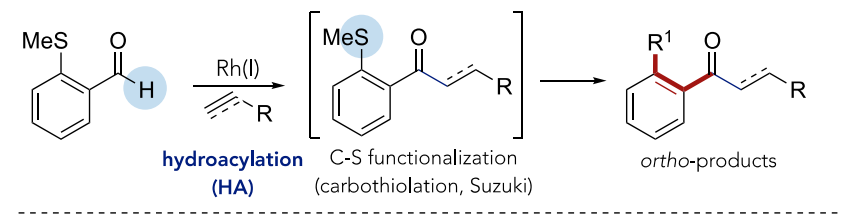

b) Hydroacylation/ortho-C-H alkylation with same alkene

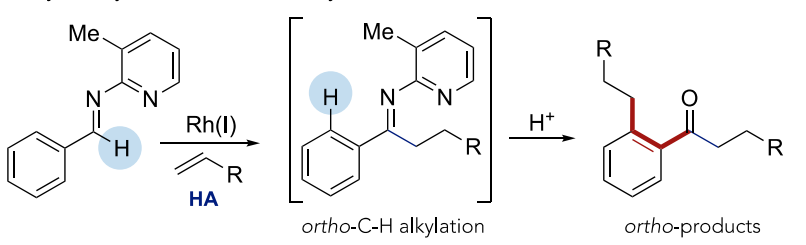

c) This work: 2-Triazenylbenzaldehydes in hydroacylation, together with sequential functionalization reactions to complex benzenes

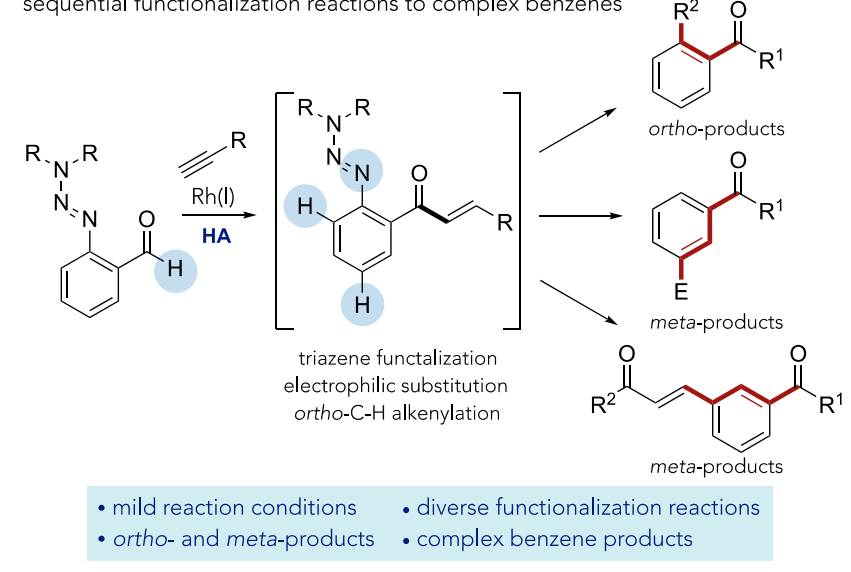

2-triazenyl groups (Scheme 1c). ${ }^{23}$ The triazene group offers many potential advantages: (1) although not previously reported, the triazene group should be capable of acting as a chelating group for metal-catalyzed intermolecular hydroacylation, with the first nitrogen atom positioned to form a stable five-membered acyl-metal-hydride complex; ${ }^{7 \mathrm{~d}}$ (2) catalyst coordination to the second nitrogen atom would direct the metal center to the ortho- $\mathrm{C}-\mathrm{H}$ bond; ${ }^{24}$ (3) the electron-donating properties of the triazene would promote electrophilic aromatic substitution reactions; (4) triazene groups can be easily removed; ${ }^{25}$ and (5) triazenes can be transformed to a wide range of alternative functional groups. ${ }^{23,24,26}$ By exploiting just a selection of these activation modes, it should be possible to access multisubstituted benzenes; these are motifs that remain of considerable worth to medicinal chemists. ${ }^{27}$ Despite the versatility of the triazene group, its use as a directing group in metal-catalyzed $\mathrm{C}-\mathrm{H}$ functionalization is rare and remains challenging. ${ }^{24}$ This is mainly due to the difficulty of controlling monofunctionalization vs difunctionalization, ${ }^{24 a, 28}$ which, in turn, limits synthetic applications. However, we were confident that our reaction design, in which a variety of chemically distinct $\mathrm{C}-\mathrm{H}$ bonds are present, would alleviate these issues. Herein, we show that it is indeed possible to use triazene groups in Rh-catalyzed chelation-controlled alkyne hydroacylation, and in a variety of further functionalization processes, allowing access to complex benzene products.

2-Triazenylbenzaldehyde starting materials were prepared from widely available anthranilic acids using simple procedures. ${ }^{29}$ With the substrates in hand, we began our investigation by evaluating a range of known hydroacylation catalysts. It quickly became apparent that the combination of $\left[\mathrm{Rh}(\mathrm{nbd})_{2}\right] \mathrm{BF}_{4}(\mathrm{nbd}=$ norbornadiene $)$ and bis (diphenylphosphinoethane) (dppe), in dichloromethane solvent at room temperature, was the most efficient catalyst system for the coupling reaction between the piperidine derivative $\mathbf{1 a}$ and a selection of terminal alkynes (see the Supporting Information for further details, as well as Scheme 2a). Excellent conversions

Scheme 2. (a) Intermolecular Hydroacylation of 2Triazenylbenzaldehyde 1a with Terminal Alkynes, and (b) Removal of the Triazene Group under Acid Conditions

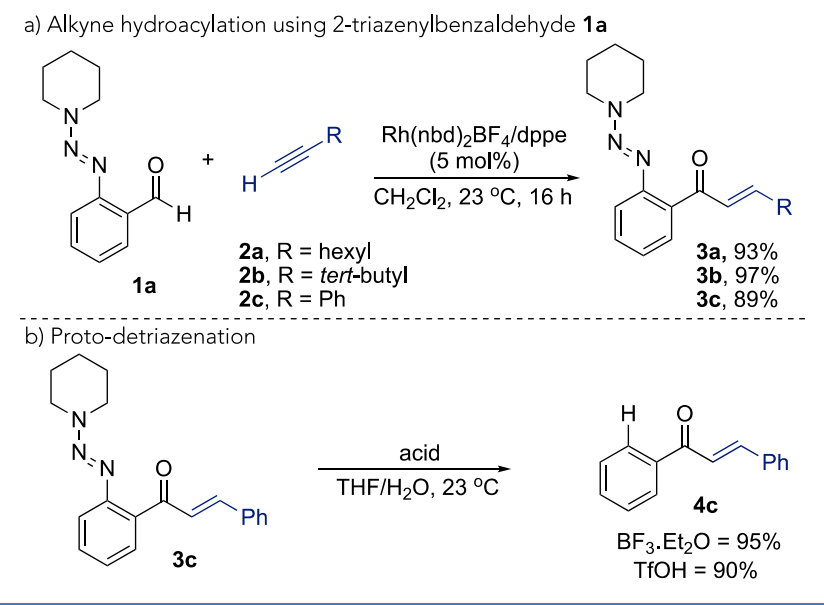

and yields were achieved with 1-octyne (2a), $t$-Bu-substituted alkyne (2b), and phenylacetylene (2c), exclusively delivering the linear isomers of the hydroacylation adducts $3 a-3 c$.

We next explored how readily the triazene group could be removed and replaced with a $\mathrm{H}$-atom (see Scheme $2 \mathrm{~b}$ ). Initial attempts using either known reducing $\left(\mathrm{H}-\mathrm{SiCl}_{3}\right)^{30}$ or acidic conditions (TFA $)^{25}$ were not successful. However, we found that by using either $\mathrm{BF}_{3} \cdot \mathrm{OEt}_{2}$ or triflic acid, the triazene group could be efficiently removed (Scheme $2 \mathrm{~b}$ ). ${ }^{31}$ The use of a $\mathrm{THF} /$ water solvent mixture was important for the success of these reactions, because it presumably aids solubility of the diazonium salt intermediate.

Next, we examined the scope of sequential hydroacylation/ triazene removal, with respect to different alkynes and 2triazenylbenzaldehydes (Scheme 3 ). The reaction was generally effective, affording good to excellent yields of the traceless hydroacylation products. Note that both transformations were performed at ambient temperature. Aldehyde 1a could be combined with a range of terminal alkynes, including those used in Scheme $2(\mathbf{4 a - 4 c )}$, as well as cycloalkyl-substituted alkynes (4d, 4e), enyne (4f), remote-aryl alkyne $(\mathbf{4 g})$, and ferrocenyl (4h) substrates. The reactions also proceeded well with a variety of different functional groups positioned around the arene core of the aldehydes; 4-chloro (4i), 4-trifluoromethyl (4j), 5-trifluoromethoxy (4k), and 5fluoro (41) substituents were all well-tolerated.

The ability of the coordinating triazene group to facilitate sequential $\mathrm{C}-\mathrm{H}$ functionalization reactions was evaluated next. Using the conditions developed by Huang for the ortho-C-H 
Scheme 3. Traceless Hydroacylation via Sequential Alkyne Hydroacylation of 2-Triazenylbenzaldehydes/Removal of the Triazene Group ${ }^{a}$

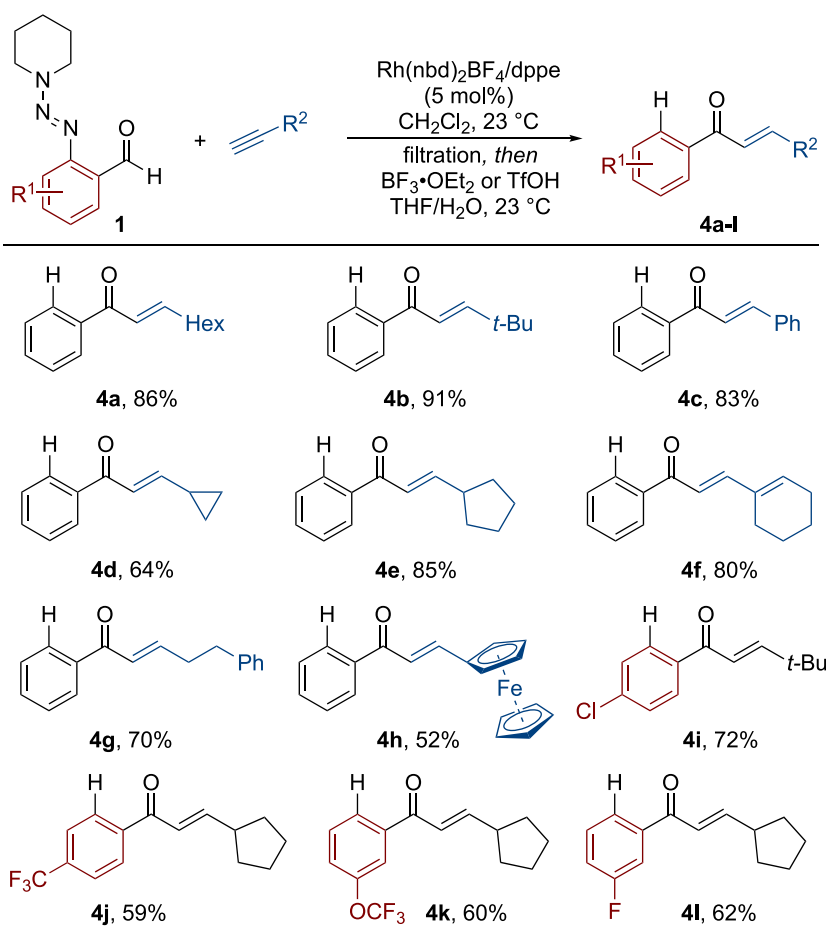

${ }^{a}$ Reaction conditions: 1 (1 equiv), alkyne (1.5 equiv), $\left[\mathrm{Rh}(\mathrm{nbd})_{2}\right] \mathrm{BF}_{4}$ (5 mol \%), dppe ( $5 \mathrm{~mol} \%), \mathrm{CH}_{2} \mathrm{Cl}_{2}, 23{ }^{\circ} \mathrm{C}, 16 \mathrm{~h}$; then, silica filtration and $\mathrm{BF}_{3} \cdot \mathrm{OEt}_{2}$ or $\mathrm{TfOH}$ (3.3-10 equiv), THF/ $\mathrm{H}_{2} \mathrm{O}, 23{ }^{\circ} \mathrm{C}, 1 \mathrm{~h}$. Isolated yields over two steps.

olefination of aryltriazenes as a starting point, ${ }^{24 a}$ we found that a $\mathrm{Rh}$ (III)-catalyst system could promote the $\mathrm{C}-\mathrm{H}$ activation of the initial hydroacylation products. Further optimization showed that the original reaction conditions could be simplified, allowing the reaction to proceed efficiently in the absence of silver co-catalysts and at lower temperatures. With the modified conditions in place, we performed the threecomponent transformations in a sequential manner, with a simple filtration through a silica pad separating the two steps (see Scheme 4). Using two distinctive catalysts, the combination of 2-triazenylbenzaldehyde $\mathbf{1 a}$ and $t$-Bu-substituted alkyne $\mathbf{2 b}$, followed by the ortho-olefination with butyl acrylate, gave the double $\mathrm{C}-\mathrm{H}$ functionalization product $\mathbf{5 a}$ in an excellent yield with absolute regiocontrol. A range of other terminal alkynes could also be employed successfully, including 1-octyne (5b), and those substituted with alkyl chloride $(\mathbf{5 c})$, phenyl (5d) and 3-thienyl (5e) groups. In addition, variation of the aldehyde component was possible; 6-fluoro (5f), 5methyl (5g), 5-fluoro (5h), 4-chloro (5i), and 2-naphthyl (5j) substrates all delivered the final products in good to excellent yields. Importantly, the reaction could be performed on increased scale, with the isolation of $1.2 \mathrm{~g}$ of benzene $5 \mathrm{f}$ showcasing the excellent practicability of the developed method.

The scope, with respect to the alkene component, was also examined. In addition to tert-butyl acrylate (5k), a selection of alkenes absent from Huang's report was also compatible with the sequential process. These compounds included acrylamide (51), phenylsulfone (5m), and styrene (5n), which afforded the corresponding products in good yields. As previously
Scheme 4. Sequential Hydroacylation/ortho-C-H Functionalization Reactions ${ }^{a}$

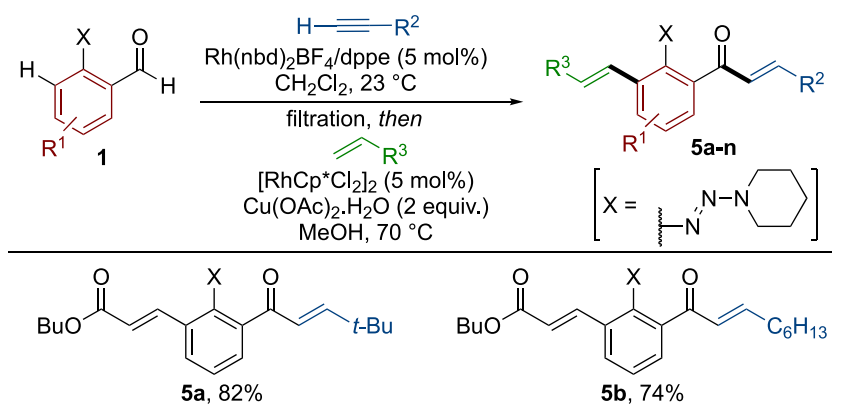<smiles>[X]c1c(/C=C/C(=O)OCCCC)cccc1C(=O)/C=C/CCCCl</smiles><smiles>[X]c1c(/C=C/C(=O)OCC)cccc1C(=O)/C=C/c1ccsc1</smiles><smiles>[X]c1c(/C=C/C(=O)OC(C)(C)C)ccc(F)c1C(=O)/C=C/C(C)(C)C</smiles><smiles>[X]c1c(/C=C/C(=O)OCC)cc(C)cc1C(=O)/C=C/C(C)(C)C</smiles><smiles>[X]c1c(C=CC(=O)OCC)cc(F)cc1C(=O)C=CC(C)(C)C</smiles><smiles>[X]c1c(C(=O)/C=C/C(C)(C)C)ccc(Cl)c1/C=C/C(=O)OCC</smiles><smiles>[X]c1c(C(=O)/C=C/C(C)(C)C)cc2ccccc2c1/C=C/C(=O)OC(C)(C)C</smiles><smiles>[X]c1c(/C=C/C(=O)OC(C)(C)C)cccc1C(=O)/C=C/C(C)(C)C</smiles><smiles>[X]c1c(/C=C/C(=O)N(C)C)cccc1C(=O)/C=C/C(C)(C)C</smiles><smiles>[X]c1cccc(C(=O)C=CC(C)(C)C)c1[X]</smiles><smiles>[X]c1c(/C=C/c2ccc(C(F)(F)F)cc2)cccc1C(=O)/C=C/C(C)(C)C</smiles>

$5 \mathrm{~m}, 68 \%$

$5 n, 58 \%$

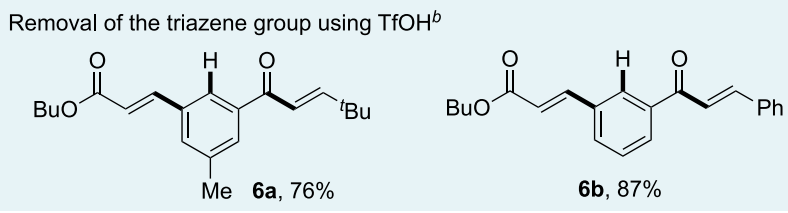

${ }^{a}$ Reaction conditions: 1 ( 1 equiv), alkyne ( 1.5 equiv), $\left[\mathrm{Rh}(\mathrm{nbd})_{2}\right] \mathrm{BF}_{4}$ ( $5 \mathrm{~mol} \%$ ), dppe $(5 \mathrm{~mol} \%), \mathrm{CH}_{2} \mathrm{Cl}_{2}, 23{ }^{\circ} \mathrm{C}, 16 \mathrm{~h}$; then, silica filtration and alkene ( 2.5 equiv), $\left[\mathrm{RhCp}^{*} \mathrm{Cl}_{2}\right]_{2}(5 \mathrm{~mol} \%), \mathrm{Cu}(\mathrm{OAc})_{2} \cdot \mathrm{H}_{2} \mathrm{O}(2$ equiv), $\mathrm{MeOH}, 70{ }^{\circ} \mathrm{C}, 16 \mathrm{~h}$. Isolated yields over two steps. ${ }^{b} \mathrm{TfOH}$ (3.3 equiv), $\mathrm{THF} / \mathrm{H}_{2} \mathrm{O}, 23{ }^{\circ} \mathrm{C}, 1 \mathrm{~h}$; Isolated yields.

noted, the triazene group could subsequently be removed using triflic acid, providing the meta-substituted products (6a and 6b).

Having explored the utility of the triazene unit as a directing group in metal-catalyzed sequential $\mathrm{C}-\mathrm{H}$ functionalization reactions, we next turned our attention to its potential use as a controlling substituent in electrophilic aromatic substitution reactions. We envisioned that the electron-donating ability of the triazene should allow simple installation of electrophiles onto the benzene core, which would, when combined with hydroacylation and triazene removal, give access to additional 
substitution patterns. Attracted by the versatility of aryl bromides in organic synthesis, we selected bromination as the transformation of choice. We found that one-pot addition of NBS to the hydroacylation reaction mixture with stirring for $1 \mathrm{~h}$ at room temperature resulted in para-selective bromination, relative to the triazene substituent. In situ removal of the triazene could be achieved as observed previously, to afford the meta-substituted bromo enone products 7 (see Scheme 5).

Scheme 5. Meta-selective One-Pot Hydroacylation/ Bromination, Followed by Removal of the Triazene Group ${ }^{a}$

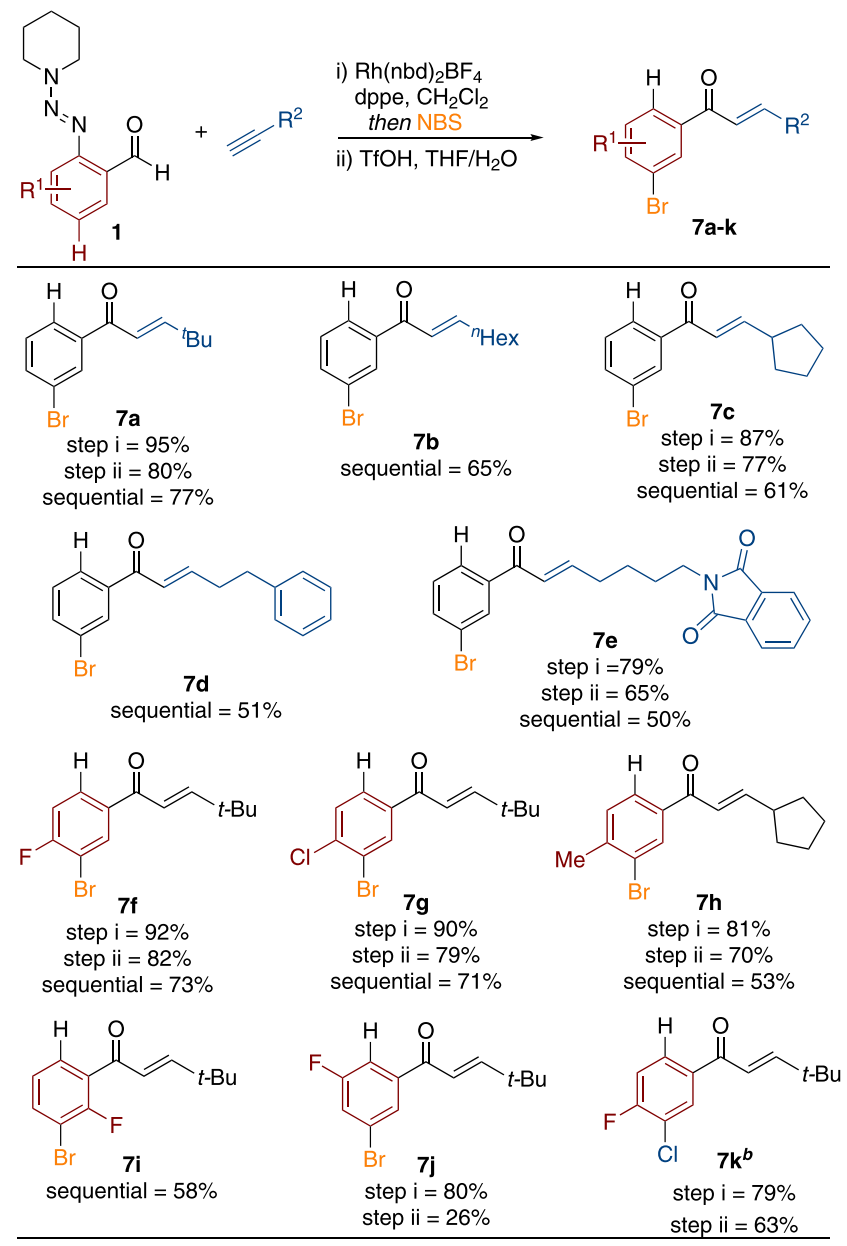

${ }^{a}$ Reaction conditions: (i) 1 ( 1 equiv), alkynes (1.5 equiv), $\left[\mathrm{Rh}(\mathrm{nbd})_{2}\right] \mathrm{BF}_{4}(5 \mathrm{~mol} \%)$, dppe $(5 \mathrm{~mol} \%), \mathrm{CH}_{2} \mathrm{Cl}_{2}, 23{ }^{\circ} \mathrm{C}, 16 \mathrm{~h}$; then NBS (1.5 equiv), 23 or $40{ }^{\circ} \mathrm{C}, 1-1.5 \mathrm{~h}$, (ii) TfOH ( 3.3 equiv), $\mathrm{THF} / \mathrm{H}_{2} \mathrm{O}, 23{ }^{\circ} \mathrm{C}, 1 \mathrm{~h}$; Sequential yields = yields over two steps, obtained using one silica purification. ${ }^{b} 1$-chloro-1,2-benziodoxol-3one used in place of NBS.

Bromination using an isolated hydroacylation product confirmed that the process was not metal-catalyzed. In addition, a control reaction established that a simple $(E)$ chalcone was unreactive under these reaction conditions, confirming the requirement for the triazene group. The scope of the one-pot hydroacylation/bromination was general, and a range of alkynes and aldehydes could be employed successfully. tert-Butyl (7a), 1-octyne (7b), and cyclopentyl (7c) substrates were efficiently transformed to the corresponding sequential products. Phenyl- (7d) and phthalimide-substituted (7e) alkyl examples were also compatible. Bromination of the nontriazene-substituted aromatic rings was not observed in these substrates, establishing the high regioselectivity of this reaction. 2-Triazenylbenzaldehydes substituted with 4-fluoro (7f), 4chloro $(7 \mathbf{g})$, 4-methyl $(7 \mathbf{h})$, or 6-fluoro $(7 \mathbf{i})$ were also suitable substrates, affording the meta-bromo products in good yields. The 3-fluoro (7j) substrate was also well-tolerated for one-pot hydroacylation/bromination, but triazene removal was inefficient. Chlorination could also be achieved if NBS was replaced with 1-chloro-1,2-benziodoxol-3-one, ${ }^{32}$ with metachloro-variant $(\mathbf{7 k})$ obtained in good yield. The mild reaction conditions and high yields achieved for these meta-halogenated products complements recent metal-catalyzed variants, ${ }^{33}$ which often require forcing reaction conditions and specific electronpoor substrates.

Until this point, functionalization of the triazene substituent had only involved conversion to a $\mathrm{H}$ atom. However, the full potential of this group was established by transformation to a diverse set of products. ${ }^{23}$ For example, Pd-catalyzed crosscoupling of triazene-containing hydroacylation adduct $3 \mathrm{c}$ with an aryl boronic acid delivered the arylation product 8 in $88 \%$ yield (Scheme 6). ${ }^{34}$ Alternatively, treatment of $3 \mathrm{c}$ with $\mathrm{MeI}$

Scheme 6. Transformations of the Triazene Group Using Hydroacylation Adduct 3c

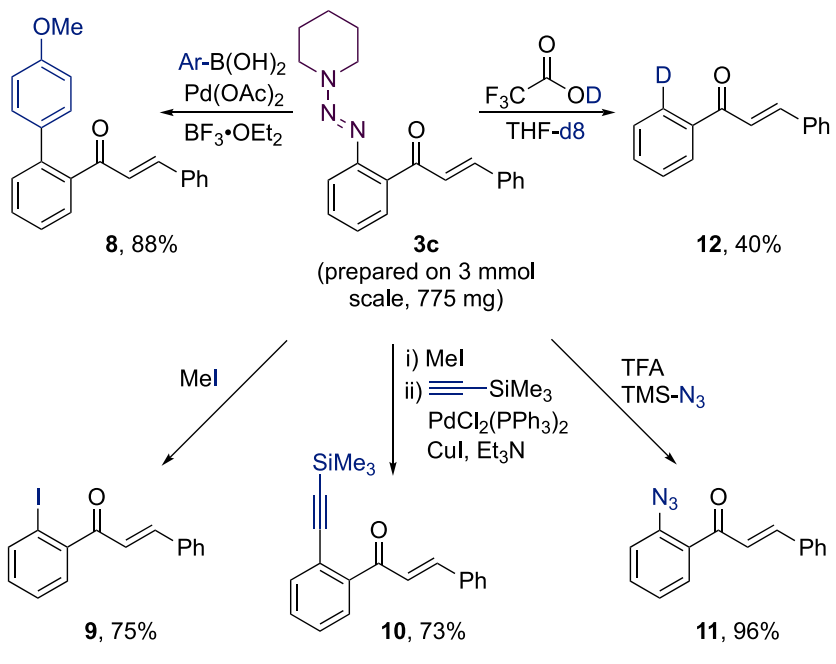

provided the corresponding aryl iodide $9{ }^{28}$ which could either be isolated, or reacted directly in a Pd-catalyzed Sonogashiracoupling reaction to deliver alkyne 10 . Reaction of $3 \mathrm{c}$ with TMS- $\mathrm{N}_{3}$ afforded the azide-substituted enone 11 in excellent yield. ${ }^{28}$ The triazene group could also be converted to a deuterium atom via treatment with deuterated TFA and deuterated THF (12). ${ }^{35}$

Having established a series of transformations that exploit the triazene substituent of hydroacylation adducts, we then combined several of these reactions with hydroacylation (Scheme 7). Because of the importance of polyaromatic compounds, the Pd-catalyzed detriazenative-arylation reaction was further studied in a sequential manner (Scheme 7a). 4Methyl (13a), 2-methyl (13b), and 3-chloro-4-methoxy (13c) aryl boronic acids were combined with 3-fluoro, 4-chloro, and 6-fluoro substrates, respectively, following hydroacylation, giving the biaryl products in excellent yields. Although the addition of a Pd catalyst is required for the arylation step, the overall catalyst loading of the $\mathrm{Rh}(\mathrm{I})$ complex is reduced, no oxidant is needed, less-costly reagents are used, and at a lower temperature, when compared to the earlier reported cascade 
Scheme 7. (a) Sequential Hydroacylation/Detriazenative Arylation, (b) One-Pot Hydroacylation/1,4-Conjugate Addition Followed by Arylation, and (c) Multiple $\mathrm{C}-\mathrm{H}$ Functionalizations Followed by Suzuki Coupling

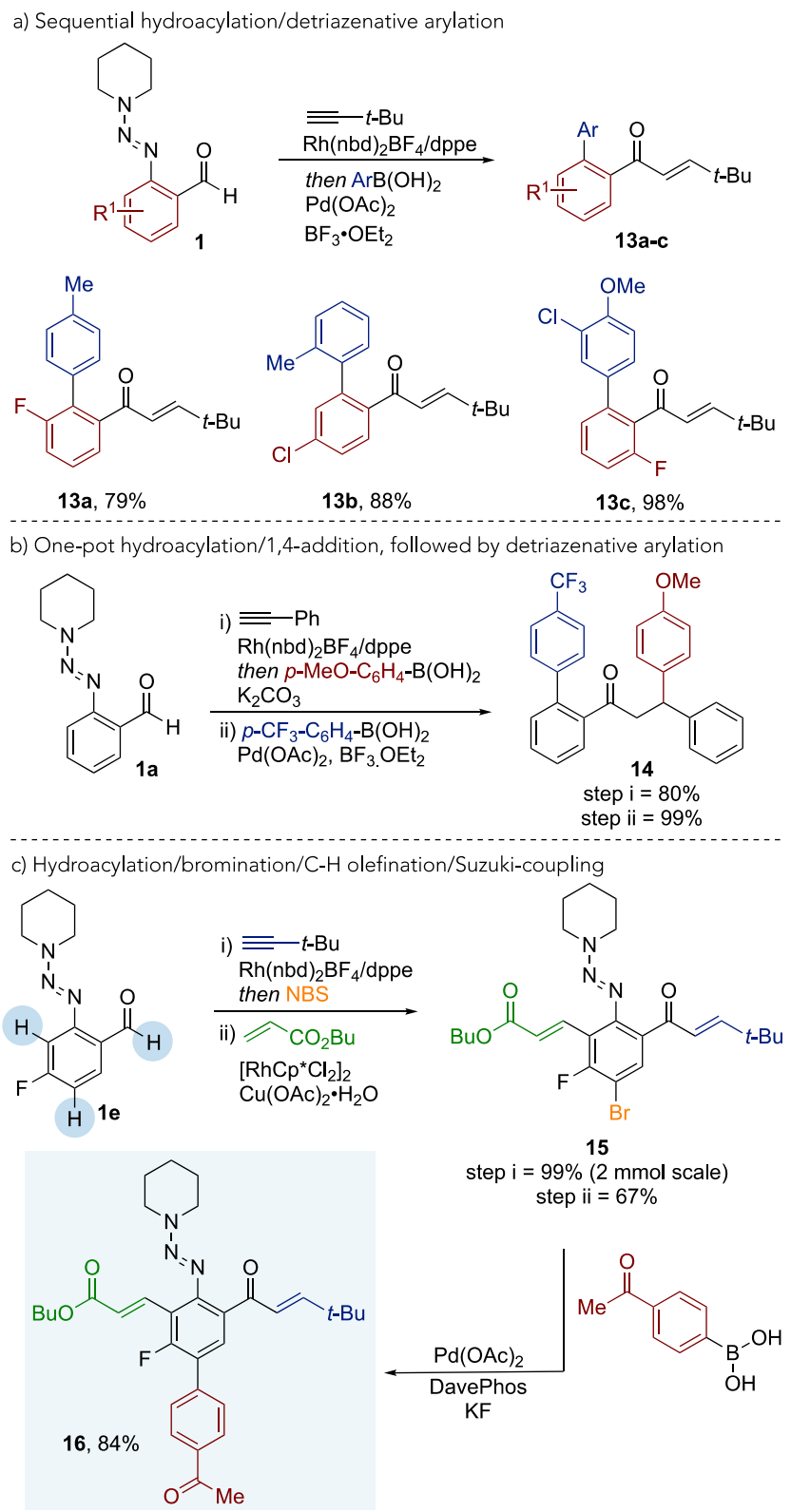

$\mathrm{C}-\mathrm{S}$ activation process. ${ }^{21 \mathrm{a}}$ Using a single $\mathrm{Rh}(\mathrm{I})$ complex, as previously reported by our laboratory, it was possible to achieve sequential alkyne hydroacylation and aryl boronic acid conjugate addition into the enone (Scheme $7 \mathrm{~b}) .{ }^{18 \mathrm{c}}$ The triazene group remained intact during these one-pot reactions, and it could then be exploited in a Pd-catalyzed coupling reaction with a further aryl boronic acid to afford polyaryl ketone 14 in a selective manner. Finally, alkyne hydroacylation, para-bromination, and ortho-olefination could be combined to achieve three successive $\mathrm{C}-\mathrm{H}$ functionalization reactions, delivering complex pentasubstituted benzene $\mathbf{1 5}$ in a simple procedure. The Pd-catalyzed Suzuki-coupling of 15 was also possible, and it afforded the arylation product $\mathbf{1 6}$.

In summary, we have shown that a dppe-Rh(I) complex can catalyze alkyne hydroacylation of 2-triazenylbenzaldehydes. The versatility of the triazene chelating group enables a variety of sequential transformations, including ortho- $\mathrm{C}-\mathrm{H}$ olefination, para-bromination, and a range of detriazenative functionalizations. Each class of sequential reaction utilizes mild reaction conditions and tolerates a broad range of functional groups, delivering traceless-, ortho- and metasubstituted hydroacylation products. The ability to link together multiple distinct transformations in a selective and efficient manner demonstrates the versatility of triazenyl aldehyde substrates for the preparation of complex benzenes, which remain valuable motifs in drug discovery. ${ }^{27}$

\section{ASSOCIATED CONTENT}

Supporting Information

The Supporting Information is available free of charge at https://pubs.acs.org/doi/10.1021/acscatal.1c01722.

Experimental procedures and supporting characterization data and spectra (PDF)

\section{AUTHOR INFORMATION}

\section{Corresponding Author}

Michael C. Willis - Department of Chemistry, Chemistry

Research Laboratory, University of Oxford, Oxford OX1

3TA, United Kingdom; 이이.org/0000-0002-0636-

6471; Email: michael.willis@chem.ox.ac.uk

\section{Authors}

Sangwon Seo - Department of Chemistry, Chemistry Research Laboratory, University of Oxford, Oxford OX1 3TA, United Kingdom; o orcid.org/0000-0003-2281-9167

Ming Gao - Department of Chemistry, Chemistry Research Laboratory, University of Oxford, Oxford OX1 3TA, United Kingdom

Eva Paffenholz - Department of Chemistry, Chemistry Research Laboratory, University of Oxford, Oxford OX1 3TA, United Kingdom

Complete contact information is available at: https://pubs.acs.org/10.1021/acscatal.1c01722

\section{Notes}

The authors declare no competing financial interest.

\section{ACKNOWLEDGMENTS}

This work was supported by the EPSRC (No. EP/K024205/ 1).

\section{REFERENCES}

(1) (a) Lam, N. Y. S.; Wu, K.; Yu, J. Q. Advancing the Logic of Chemical Synthesis: $\mathrm{C}-\mathrm{H}$ Activation as Strategic and Tactical Disconnections for $\mathrm{C}-\mathrm{C}$ Bond Construction. Angew. Chem., Int. Ed. 2021, in press, DOI: 10.1002/anie.202011901. (b) Gandeepan, P.; Muller, T.; Zell, D.; Cera, G.; Warratz, S.; Ackermann, L. 3d Transition Metals for C-H Activation. Chem. Rev. 2019, 119, 21922452. (c) Davies, H. M. L.; Morton, D. Collective Approach to Advancing C-H Functionalization. ACS Cent. Sci. 2017, 3, 936-943. (d) Davies, H. M.; Morton, D. Recent Advances in C-H Functionalization. J. Org. Chem. 2016, 81, 343-350.

(2) Gensch, T.; Hopkinson, M. N.; Glorius, F.; Wencel-Delord, J. Mild metal-catalyzed C-H activation: examples and concepts. Chem. Soc. Rev. 2016, 45, 2900-2936.

(3) (a) Gandeepan, P.; Ackermann, L. Transient Directing Groups for Transformative $\mathrm{C}-\mathrm{H}$ Activation by Synergistic Metal Catalysis. Chem. 2018, 4, 199-222. (b) Engle, K. M.; Mei, T.-S.; Wasa, M.; Yu, J.-Q. Weak Coordination as a Powerful Means for Developing Broadly Useful C-H Functionalization Reactions. Acc. Chem. Res. 2012, 45, 
788-802. (c) Lyons, T. W.; Sanford, M. S. Palladium-Catalyzed Ligand-Directed C-H Functionalization Reactions. Chem. Rev. 2010, 110, 1147-1169. (d) Colby, D. A.; Bergman, R. G.; Ellman, J. A. Rhodium-Catalyzed C-C Bond Formation via Heteroatom-Directed C-H Bond Activation. Chem. Rev. 2010, 110, 624-655.

(4) Mandal, A.; Dana, S.; Chowdhury, D.; Baidya, M. Recent Advancements in Transition-Metal-Catalyzed One-Pot Twofold Unsymmetrical Difunctionalization of Arenes. Chem. - Asian J. 2019, 14, 4074-4086.

(5) (a) Sarkar, D.; Gulevich, A. V.; Melkonyan, F. S.; Gevorgyan, V. Synthesis of Multisubstituted Arenes via PyrDipSi-Directed Unsymmetrical Iterative $\mathrm{C}-\mathrm{H}$ Functionalizations. ACS Catal. 2015, 5, 6792-6801. (b) Gulevich, A. V.; Melkonyan, F. S.; Sarkar, D.; Gevorgyan, V. Double-fold C-H oxygenation of arenes using PyrDipSi: a general and efficient traceless/modifiable silicon-tethered directing group. J. Am. Chem. Soc. 2012, 134, 5528-5531. (c) Zhang, S. Y.; Li, Q.; He, G.; Nack, W. A.; Chen, G. Pd-catalyzed monoselective ortho-C-H alkylation of $\mathrm{N}$-quinolyl benzamides: evidence for stereoretentive coupling of secondary alkyl iodides. $J$. Am. Chem. Soc. 2015, 137, 531-539. (d) Kim, H. J.; Ajitha, M. J.; Lee, Y.; Ryu, J.; Kim, J.; Lee, Y.; Jung, Y.; Chang, S. Hydrogen-bondassisted controlled $\mathrm{C}-\mathrm{H}$ functionalization via adaptive recognition of a purine directing group. J. Am. Chem. Soc. 2014, 136, 1132-1140. (e) Engle, K. M.; Wang, D. H.; Yu, J. Q. Constructing multiply substituted arenes using sequential palladium(II)-catalyzed C-H olefination. Angew. Chem., Int. Ed. 2010, 49, 6169-6173. (f) Li, J.; Korvorapun, K.; De Sarkar, S.; Rogge, T.; Burns, D. J.; Warratz, S.; Ackermann, L. Ruthenium(II)-catalysed remote $\mathrm{C}-\mathrm{H}$ alkylations as a versatile platform to meta-decorated arenes. Nat. Commun. 2017, 8, 15430. (g) Ghosh, K.; Rit, R. K.; Ramesh, E.; Sahoo, A. K. Ruthenium-Catalyzed Hydroarylation and One-Pot Twofold Unsymmetrical C-H Functionalization of Arenes. Angew. Chem., Int. Ed. 2016, 55, 7821-7825.

(6) (a) Sakai, K.; Oda, O.; Nakamura, N.; Ide, J. Synthetic Studies on Prostanoids 1 Synthesis of Methyl 9-Oxoprostanoate. Tetrahedron Lett. 1972, 13, 1287-1290. (b) Tsuji, J.; Ohno, K. Organic syntheses by means of noble metal compounds XXI. Decarbonylation of aldehydes using rhodium complex. Tetrahedron Lett. 1965, 6, 39693971.

(7) (a) Davison, R. T.; Kuker, E. L.; Dong, V. M. Teaching Aldehydes New Tricks Using Rhodium- and Cobalt-Hydride Catalysis. Acc. Chem. Res. 2021, 54, 1236-1250. (b) Ghosh, A.; Johnson, K. F.; Vickerman, K. L.; Walker, J. A.; Stanley, L. M. Recent advances in transition metal-catalysed hydroacylation of alkenes and alkynes. Org. Chem. Front. 2016, 3, 639-644. (c) Dong, V. M.; Kou, K. G. M.; Le, D. N. Transition-Metal-Catalyzed Hydroacylation. In Organic Reactions; Wiley: Hoboken, NJ, 2018; pp 231-592, . (d) Willis, M. C. Transition Metal Catalyzed Alkene and Alkyne Hydroacylation. Chem. Rev. 2010, 110, 725-748. (e) Jun, C.-H.; Jo, E.-A.; Park, J.-W. Intermolecular Hydroacylation by Transition-Metal Complexes. Eur. J. Org. Chem. 2007, 2007, 1869-1881.

(8) Leung, J. C.; Krische, M. J. Catalytic intermolecular hydroacylation of $\mathrm{C}-\mathrm{C} \pi$-bonds in the absence of chelation assistance. Chem. Sci. 2012, 3, 2202-2209.

(9) (a) Ding, W.; Ho, Y. K. T.; Okuda, Y.; Wijaya, C. K.; Tan, Z. H.; Yoshikai, N. Cobalt-Catalyzed Hydroacylative Dimerization of Allenes Leading to Skipped Dienes. Org. Lett. 2019, 21, 6173-6178. (b) Yatabe, T.; Mizuno, N.; Yamaguchi, K. Transition-Metal-Free Catalytic Formal Hydroacylation of Terminal Alkynes. ACS Catal. 2018, 8, 11564-11569. (c) Kim, J.; Yi, C. S. Intermolecular Markovnikov-Selective Hydroacylation of Olefins Catalyzed by a Cationic Ruthenium-Hydride Complex. ACS Catal. 2016, 6, 33363339. (d) Xiao, L.-J.; Fu, X.-N.; Zhou, M.-J.; Xie, J.-H.; Wang, L.-X.; Xu, X.-F.; Zhou, Q.-L. Nickel-Catalyzed Hydroacylation of Styrenes with Simple Aldehydes: Reaction Development and Mechanistic Insights. J. Am. Chem. Soc. 2016, 138, 2957-2960. (e) Chen, Q.-A.; Cruz, F. A.; Dong, V. M. Alkyne Hydroacylation: Switching Regioselectivity by Tandem Ruthenium Catalysis. J. Am. Chem. Soc. 2015, 137, 3157-3160. (f) Chen, Q. A.; Kim, D. K.; Dong, V. M.
Regioselective hydroacylation of 1,3-dienes by cobalt catalysis. J. Am. Chem. Soc. 2014, 136, 3772-3775. (g) Shibahara, F.; Bower, J. F.; Krische, M. J. Diene Hydroacylation from the Alcohol or Aldehyde Oxidation Level via Ruthenium-Catalyzed C-C Bond-Forming Transfer Hydrogenation: Synthesis of $\beta, \gamma$-Unsaturated Ketones. J. Am. Chem. Soc. 2008, 130, 14120-14122. (h) Omura, S.; Fukuyama, T.; Horiguchi, J.; Murakami, Y.; Ryu, I. Ruthenium HydrideCatalyzed Addition of Aldehydes to Dienes Leading to $\beta, \gamma$ Unsaturated Ketones. J. Am. Chem. Soc. 2008, 130, 14094-14095. (i) Roy, A. H.; Lenges, C. P.; Brookhart, M. Scope and Mechanism of the Intermolecular Addition of Aromatic Aldehydes to Olefins Catalyzed by $\mathrm{Rh}(\mathrm{I})$ Olefin Complexes. J. Am. Chem. Soc. 2007, 129, 2082-2093. (j) Lenges, C. P.; Brookhart, M. Co(I)-Catalyzed Interand Intramolecular Hydroacylation of Olefins with Aromatic Aldehydes. J. Am. Chem. Soc. 1997, 119, 3165-3166. (k) Tsuda, T.; Kiyoi, T.; Saegusa, T. Nickel(0)-catalyzed hydroacylation of alkynes with aldehydes to alpha, beta.-enones. J. Org. Chem. 1990, 55, 2554-2558. (1) Marder, T. B.; Roe, D. C.; Milstein, D. Transitionmetal-catalyzed carbon-carbon bond formation via carbon-hydrogen activation. Intermolecular hydroacylation: the addition of aldehydes to alkenes. Organometallics 1988, 7, 1451-1453.

(10) Lee, H.; Jun, C. H. Hydroacylation of 1-Alkene with 2(Diphenylphosphino)Benzaldehyde by Rh(I). Bull. Korean Chem. Soc. 1995, 16, 66-68.

(11) (a) Li, H. S.; Lu, S. C.; Chang, Z. X.; Hao, L.; Li, F. R.; Xia, C. Rhodium-Catalyzed Ring-Opening Hydroacylation of Alkylidenecyclopropanes with Chelating Aldehydes for the Synthesis of gamma, delta-Unsaturated Ketones. Org. Lett. 2020, 22, 5145-5150. (b) Murphy, S. K.; Petrone, D. A.; Coulter, M. M.; Dong, V. M. Catalytic Hydroacylation as an Approach to Homoaldol Products. Org. Lett. 2011, 13, 6216-6219. (c) Coulter, M. M.; Kou, K. G. M.; Galligan, B.; Dong, V. M. Regio- and Enantioselective Intermolecular Hydroacylation: Substrate-Directed Addition of Salicylaldehydes to Homoallylic Sulfides. J. Am. Chem. Soc. 2010, 132, 16330-16333. (d) Kokubo, K.; Matsumasa, K.; Miura, M.; Nomura, M. RhodiumCatalyzed Coupling Reaction of Salicyl Aldehydes with Alkynes via Cleavage of the Aldehyde C-H Bond. J. Org. Chem. 1997, 62, 45644565. (e) Imai, M.; Tanaka, M.; Tanaka, K.; Yamamoto, Y.; ImaiOgata, N.; Shimowatari, M.; Nagumo, S.; Kawahara, N.; Suemune, H. Double-Chelation-Assisted Rh-Catalyzed Intermolecular Hydroacylation between Salicylaldehydes and 1,4-Penta- or 1,5-Hexadienes. J. Org. Chem. 2004, 69, 1144-1150. (f) Barwick-Silk, J.; Hardy, S.; Willis, M. C.; Weller, A. S. Rh(DPEPhos)-Catalyzed Alkyne Hydroacylation Using beta-Carbonyl-Substituted Aldehydes: Mechanistic Insight Leads to Low Catalyst Loadings that Enables Selective Catalysis on Gram-Scale. J. Am. Chem. Soc. 2018, 140, 7347-7357. (g) Coxon, T. J.; Fernandez, M.; Barwick-Silk, J.; McKay, A. I.; Britton, L. E.; Weller, A. S.; Willis, M. C. Exploiting Carbonyl Groups to Control Intermolecular Rhodium-Catalyzed Alkene and Alkyne Hydroacylation. J. Am. Chem. Soc. 2017, 139, 10142-10149.

(12) (a) Straker, R. N.; Formica, M.; Lupton, J. D.; Niu, J.; Willis, M. C. An enamine controlling group for rhodium-catalyzed intermolecular hydroacylation. Tetrahedron 2018, 74, 5408-5414. (b) Zhang, T.; Qi, Z.; Zhang, X.; Wu, L.; Li, X. Rh(III)-catalyzed hydroacylation reactions between $\mathrm{N}$-sulfonyl 2-aminobenzaldehydes and olefins. Chem. - Eur. J. 2014, 20, 3283-3287. (c) Castaing, M.; Wason, S. L.; Estepa, B.; Hooper, J. F.; Willis, M. C. 2-Aminobenzaldehydes as Versatile Substrates for Rhodium-Catalyzed Alkyne Hydroacylation: Application to Dihydroquinolone Synthesis. Angew. Chem., Int. Ed. 2013, 52, 13280-13283. (d) Jun, C.-H.; Lee, H.; Hong, J.-B.; Kwon, B.-I. Efficient and Selective Hydroacylation of 1-Alkynes with Aldehydes by a Chelation-Assisted Catalytic System. Angew. Chem., Int. Ed. 2002, 41, 2146-2147. (e) Jun, C. H.; Lee, D. Y.; Lee, H.; Hong, J. B. A highly active catalyst system for intermolecular hydroacylation. Angew. Chem., Int. Ed. 2000, 39, 3070-3072.

(13) (a) Hooper, J. F.; Seo, S.; Truscott, F. R.; Neuhaus, J. D.; Willis, M. C. alpha-Amino Aldehydes as Readily Available Chiral Aldehydes for Rh-Catalyzed Alkyne Hydroacylation. J. Am. Chem. Soc. 2016, 138, 1630-1634. (b) Chaplin, A. B.; Hooper, J. F.; Weller, A. S.; Willis, M. 
C. Intermolecular Hydroacylation: High Activity Rhodium Catalysts Containing Small-Bite-Angle Diphosphine Ligands. J. Am. Chem. Soc. 2012, 134, 4885-4897. (c) Pawley, R. J.; Moxham, G. L.; Dallanegra, R.; Chaplin, A. B.; Brayshaw, S. K.; Weller, A. S.; Willis, M. C. Controlling Selectivity in Intermolecular Alkene or Aldehyde Hydroacylation Reactions Catalyzed by $\{\mathrm{Rh}(\mathrm{L}-2)\}(+)$ Fragments. Organometallics 2010, 29, 1717-1728. (d) Willis, M. C.; Woodward, R. L. Rhodium-catalyzed reductive aldol reactions using aldehydes as the stoichiometric reductants. J. Am. Chem. Soc. 2005, 127, 1801218013 For an intramoleculer example, see:. (e) Bendorf, H. D.; Colella, C. M.; Dixon, E. C.; Marchetti, M.; Matukonis, A. N.; Musselman, J. D.; Tiley, T. A. Chelation-assisted intramolecular hydroacylation: synthesis of medium ring sulfur heterocycles. Tetrahedron Lett. 2002, 43, 7031-7034.

(14) (a) Murphy, S. K.; Bruch, A.; Dong, V. M. Mechanistic insights into hydroacylation with non-chelating aldehydes. Chem. Sci. 2015, 6, 174-180. (b) Murphy, S. K.; Bruch, A.; Dong, V. M. Substratedirected hydroacylation: Rhodium-catalyzed coupling of vinylphenols and nonchelating aldehydes. Angew. Chem., Int. Ed. 2014, 53, 24552459.

(15) (a) Gonzalez-Rodriguez, C.; Pawley, R. J.; Chaplin, A. B.; Thompson, A. L.; Weller, A. S.; Willis, M. C. Rhodium-Catalyzed Branched-Selective Alkyne Hydroacylation: A Ligand-Controlled Regioselectivity Switch. Angew. Chem., Int. Ed. 2011, 50, 51345138. (b) Zhang, H.-J.; Bolm, C. Highly Regioselective Intermolecular Hydroacylations of Enamides with Salicylaldehydes. Org. Lett. 2011, 13, 3900-3903. (c) Murphy, S. K.; Coulter, M. M.; Dong, V. M. $\beta$ hydroxy ketones prepared by regioselective hydroacylation. Chem. Sci. 2012, 3, 355-358.

(16) Murphy, S. K.; Dong, V. M. Enantioselective hydroacylation of olefins with rhodium catalysts. Chem. Commun. 2014, 50, 1364513649.

(17) (a) Phan, D. H. T.; Kou, K. G. M.; Dong, V. M. Enantioselective Desymmetrization of Cyclopropenes by Hydroacylation. J. Am. Chem. Soc. 2010, 132, 16354-16355. (b) Osborne, J. D.; Randell-Sly, H. E.; Currie, G. S.; Cowley, A. R.; Willis, M. C. Catalytic Enantioselective Intermolecular Hydroacylation: RhodiumCatalyzed Combination of beta-S-Aldehydes and 1,3-Disubstituted Allenes. J. Am. Chem. Soc. 2008, 130, 17232-17233. (c) GonzalezRodriguez, C.; Parsons, S. R.; Thompson, A. L.; Willis, M. C. Rhodium-Catalysed Intermolecular Alkyne Hydroacylation: The Enantioselective Synthesis of alpha- and beta-Substituted Ketones by Kinetic Resolution. Chem. - Eur. J. 2010, 16, 10950-10954.

(18) (a) Straker, R. N.; Majhail, M. K.; Willis, M. C. Exploiting rhodium-catalysed ynamide hydroacylation as a platform for divergent heterocycle synthesis. Chem. Sci. 2017, 8, 7963-7968. (b) Gao, M.; Willis, M. C. Enantioselective Three-Component Assembly of beta'Aryl Enones Using a Rhodium-Catalyzed Alkyne Hydroacylation/Aryl Boronic Acid Conjugate Addition Sequence. Org. Lett. 2017, 19, 2734-2737. (c) Fernández, M.; Castaing, M.; Willis, M. C. Sequential catalysis: exploiting a single rhodium(i) catalyst to promote an alkyne hydroacylation-aryl boronic acid conjugate addition sequence. Chem. Sci. 2017, 8, 536-540. (d) Majhail, M. K.; Ylioja, P. M.; Willis, M. C. Direct Synthesis of Highly Substituted Pyrroles and Dihydropyrroles Using Linear Selective Hydroacylation Reactions. Chem. - Eur. J. 2016, 22, 7879-7884. (e) Neuhaus, J. D.; Morrow, S. M.; Brunavs, M.; Willis, M. C. Diversely Substituted Quinolines via RhodiumCatalyzed Alkyne Hydroacylation. Org. Lett. 2016, 18, 1562-1565. (f) Du, X. W.; Stanley, L. M. Tandem Alkyne Hydroacylation and Oxo-Michael Addition: Diastereoselective Synthesis of 2,3-Disubstituted Chroman-4-ones and Fluorinated Derivatives. Org. Lett. 2015, 17, 3276-3279. (g) von Delius, M.; Le, C. M.; Dong, V. M. Rhodium-Phosphoramidite Catalyzed Alkene Hydroacylation: Mechanism and Octaketide Natural Product Synthesis. J. Am. Chem. Soc. 2012, 134, 15022-15032. (h) Lenden, P.; Entwistle, D. A.; Willis, M. C. An Alkyne Hydroacylation Route to Highly Substituted Furans. Angew. Chem., Int. Ed. 2011, 50, 10657-10660. (i) Willis, M. C.; Sapmaz, S. Intermolecular hydroacylation of acrylate esters: a new route to 1,4-dicarbonyls. Chem. Commun. 2001, 2558-2559.
(19) Bouisseau, A.; Glancy, J.; Willis, M. C. Two-Component Assembly of Thiochroman-4-ones and Tetrahydrothiopyran-4-ones Using a Rhodium-Catalyzed Alkyne Hydroacylation/Thio-ConjugateAddition Sequence. Org. Lett. 2016, 18, 5676-5679.

(20) Bouisseau, A.; Gao, M.; Willis, M. C. Traceless RhodiumCatalyzed Hydroacylation Using Alkyl Aldehydes: The Enantioselective Synthesis of beta-Aryl Ketones. Chem. - Eur. J. 2016, 22, $15624-15628$.

(21) (a) Hooper, J. F.; Young, R. D.; Pernik, I.; Weller, A. S.; Willis, M. C. Carbon-carbon bond construction using boronic acids and aryl methyl sulfides: orthogonal reactivity in Suzuki-type couplings. Chem. Sci. 2013, 4, 1568-1572. (b) Hooper, J. F.; Young, R. D.; Weller, A. S.; Willis, M. C. Traceless Chelation-Controlled Rhodium-Catalyzed Intermolecular Alkene and Alkyne Hydroacylation. Chem. - Eur. J. 2013, 19, 3125-3130. (c) Hooper, J. F.; Chaplin, A. B.; GonzalezRodriguez, C.; Thompson, A. L.; Weller, A. S.; Willis, M. C. Aryl Methyl Sulfides as Substrates for Rhodium-Catalyzed Alkyne Carbothiolation: Arene Functionalization with Activating Group Recycling. J. Am. Chem. Soc. 2012, 134, 2906-2909.

(22) Jun, C.-H.; Hong, J.-B.; Kim, Y.-H.; Chung, K.-Y. The Catalytic Alkylation of Aromatic Imines by Wilkinson's Complex: The Domino Reaction of Hydroacylation and ortho-Alkylation. Angew. Chem., Int. Ed. 2000, 39, 3440-3442.

(23) (a) Suleymanov, A. A.; Severin, K. Vinyl and Alkynyl Triazenes: Synthesis, Reactivity, and Applications. Angew. Chem., Int. Ed. 2021, 60, 6879-6889. (b) Bräse, S. The Virtue of the Multifunctional Triazene Linkers in the Efficient Solid-Phase Synthesis of Heterocycle Libraries. Acc. Chem. Res. 2004, 37, 805-816. (c) Kimball, D. B.; Haley, M. M. Triazenes: A Versatile Tool in Organic Synthesis. Angew. Chem., Int. Ed. 2002, 41, 3338-3351.

(24) (a) Wang, C.; Chen, H.; Wang, Z.; Chen, J.; Huang, Y. Rhodium(III)-catalyzed C-H activation of arenes using a versatile and removable triazene directing group. Angew. Chem., Int. Ed. 2012, 51, 7242-7245. (b) Wang, C.; Sun, H.; Fang, Y.; Huang, Y. General and efficient synthesis of indoles through triazene-directed C-H annulation. Angew. Chem., Int. Ed. 2013, 52, 5795-5798. (c) Sun, H.; Wang, C.; Yang, Y. F.; Chen, P.; Wu, Y. D.; Zhang, X.; Huang, Y. Synthesis of indolo[2,1-a] isoquinolines via a triazene-directed $\mathrm{C}-\mathrm{H}$ annulation cascade. J. Org. Chem. 2014, 79, 11863-11872. (d) Wang, D.; Cui, S. $\mathrm{Rh}(\mathrm{III})$-catalyzed aromatic $\mathrm{C}-\mathrm{H}$ bond carbenoid functionalization oftriazenes by $\alpha$-diazomalonate. Tetrahedron 2016, $72,2725-2730$.

(25) Ando, S.; Burrows, J.; Koide, K. Synthesis of Violaceic Acid and Related Compounds through Aryl Triazene. Org. Lett. 2017, 19, 1116-1119.

(26) Tan, J. F.; Bormann, C. T.; Perrin, F. G.; Chadwick, F. M.; Severin, K.; Cramer, N. Divergent Synthesis of Densely Substituted Arenes and Pyridines via Cyclotrimerization Reactions of Alkynyl Triazenes. J. Am. Chem. Soc. 2019, 141, 10372-10383.

(27) (a) Nilova, A.; Campeau, L. C.; Sherer, E. C.; Stuart, D. R. Analysis of Benzenoid Substitution Patterns in Small Molecule Active Pharmaceutical Ingredients. J. Med. Chem. 2020, 63, 13389-13396. (b) Taylor, R. D.; MacCoss, M.; Lawson, A. D. Rings in drugs. J. Med. Chem. 2014, 57, 5845-5859.

(28) Hafner, A.; Brase, S. Ortho-trifluoromethylation of functionalized aromatic triazenes. Angew. Chem., Int. Ed. 2012, 51, 37133715.

(29) Reingruber, R.; Vanderheiden, S.; Wagner, A.; Nieger, M.; Muller, T.; Es-Sayed, M.; Bräse, S. 1-Aryl-3,3-diisopropyltriazenes: An Easily Accessible and Particularly Stable Class of Triazenes Towards Strong Basic and Lewis Acid Conditions. Eur. J. Org. Chem. 2008, 2008, 3314-3327.

(30) Lormann, M.; Dahmen, S.; Bräse, S. Hydro-dediazoniation of diazonium salts using trichlorosilane: new cleavage conditions for the T1 traceless linker1. Tetrahedron Lett. 2000, 41, 3813-3816.

(31) (a) Galli, C. Radical reactions of arenediazonium ions: An easy entry into the chemistry of the aryl radical. Chem. Rev. 1988, 88, 765792. (b) Zollinger, H. Nitrogen as Leaving Group: Dediazoniations of 
Aromatic Diazonium Ions. Angew. Chem., Int. Ed. Engl. 1978, 17, $141-150$.

(32) Wang, M.; Zhang, Y.; Wang, T.; Wang, C.; Xue, D.; Xiao, J. Story of an Age-Old Reagent: An Electrophilic Chlorination of Arenes and Heterocycles by 1-Chloro-1,2-benziodoxol-3-one. Org. Lett. 2016, 18, 1976-1979.

(33) (a) Schroder, N.; Wencel-Delord, J.; Glorius, F. High-yielding, versatile, and practical $\left[\mathrm{Rh}(\mathrm{III}) \mathrm{Cp}^{*}\right]$-catalyzed ortho bromination and iodination of arenes. J. Am. Chem. Soc. 2012, 134, 8298-8301. (b) Yang, L.; Lu, Z.; Stahl, S. S. Regioselective copper-catalyzed chlorination and bromination of arenes with $\mathrm{O}_{2}$ as the oxidant. Chem. Commun. 2009, 6460-6462. (c) Kalyani, D.; Dick, A. R.; Anani, W. Q.; Sanford, M. S. A Simple Catalytic Method for the Regioselective Halogenation of Arenes. Org. Lett. 2006, 8, 2523-2526.

(34) Feng, Z.; Xiao, Y.-L.; Zhang, X. Copper-catalyzed crosscoupling of bromozinc-difluoromethylphosphonate with iodo/bromoaryl triazenes. Org. Chem. Front. 2014, 1, 113-116.

(35) Vanderheiden, S.; Bulat, B.; Zevaco, T.; Jung, N.; Bräse, S. Solid phase synthesis of selectively deuterated arenes. Chem. Commun. 2011, 47, 9063-9065. 